\title{
Towards tactile expressions of emotion through mediated touch
}

\author{
Author(s) \\ Huisman, Gijs; Darriba Frederiks, Aduén \\ Publication date \\ 2013 \\ Document Version \\ Final published version \\ Published in \\ Computer Human Interaction (CHI) 2013
}

Link to publication

Citation for published version (APA):

Huisman, G., \& Darriba Frederiks, A. (2013). Towards tactile

expressions of emotion through mediated touch. In Computer Human

Interaction (CHI) 2013 Association for Computing Machinery.

It is not permitted to download or to forward/distribute the text or part of it without the consent of the author(s) and/or copyright holder(s), other than for strictly personal, individual use, unless the work is under an open content license (like Creative Commons).

If you believe that digital publication of certain material infringes any of your rights or (privacy) interests,

please let the Library know, stating your reasons. In case of a legitimate complaint, the Library will make the material inaccessible and/or remove it from the website. Please contact the library:

https://www.amsterdamuas.com/library/contact/questions, or send a letter to: University Library (Library of the University of Amsterdam and Amsterdam University of Applied Sciences), Secretariat, Singel 425, 1012 WP Amsterdam, The Netherlands. You will be contacted as soon as possible. 


\section{Towards Tactile Expressions of Emotion Through Mediated Touch}

Gijs Huisman

University of Twente, Human

Media Interaction Group

PO box 217

NL-7500 AE Enschede, The

Netherlands

gijs.huisman@utwente.nl

Aduén Darriba Frederiks

Amsterdam University of

Applied Sciences, Digital Life

Centre

Duivendrechtsekade 36 - 38

Amsterdam, $1096 \mathrm{AH}$, The

Netherlands

a.darriba.frederiks@hva.nl

Permission to make digital or hard copies of all or part of this work for personal or classroom use is granted without fee provided that copies are not made or distributed for profit or commercial advantage and that copies bear this notice and the full citation on the first page. To copy otherwise, or republish, to post on servers or to redistribute to lists, requires prior specific permission and/or a fee.

CHI'13, April 27 - May 2, 2013, Paris, France.

Copyright 2012 ACM 978-1-XXXX-XXXX-X/XX/XX ...\$10.00.

\begin{abstract}
In this paper we investigate the expression of emotions through mediated touch. Participants used the Tactile Sleeve for Social Touch (TaSST), a wearable sleeve that consists of a pressure sensitive input layer, and a vibration motor output layer, to record a number of expressions of discrete emotions. The aim was to investigate if participants could make meaningful distinctions in the tactile expression of the emotions.
\end{abstract}

\section{Author Keywords}

Mediated social touch; emotion; affect; haptic feedback; vibrotactile stimulation.

\section{ACM Classification Keywords}

H.5.2 [Information interfaces and presentation (e.g., $\mathrm{HCl})$ ]: User Interfaces - Haptic I/O.

\section{Introduction}

The expression of emotions in humans has been studied in great depth for facial and vocal expressions [10]. However, in his seminal work, The Expression of Emotions in Man and Animals, Darwin, in regard to affection, notes that: "A strong desire to touch the beloved person is felt; and love is expressed by this means more plainly than by any other." [3, p. 212]. Indeed, the tactile sense is vitally important in the forming of affiliative behavior and the 


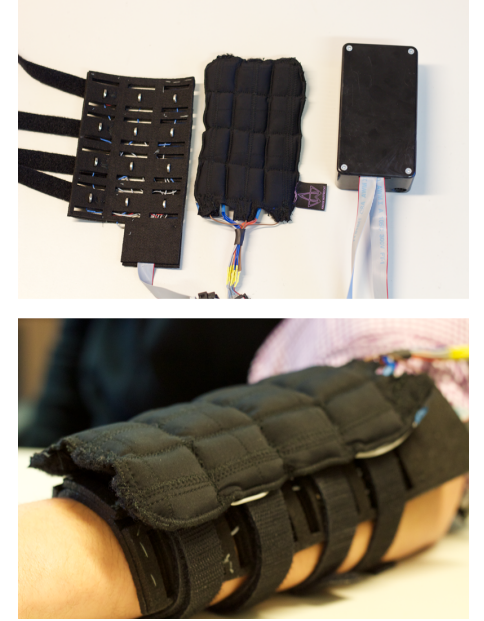

Figure 1: The TaSST. The top image shows the output layer, the input layer, and the control box. maintenance of social bonds [9]. Yet touch as a way of emotional expression has received far less attention than facial and vocal expressions. In the expression of emotions, touch has mainly been regarded as a way of communicating emotional valence, or as an intensifier of emotional displays from other modalities $[5,7]$. However, recent findings indicate that touch by itself may allow for the communication of specific emotions $[6,7]$. This notion opens up new opportunities for the expression of emotions in computer-mediated communication (CMC) and virtual reality. Emotions may not only be communicable through the visual and auditory senses but using haptic interfaces, through the tactile sense as well. Bailenson et al. [1] found that people were able to express and recognize specific emotions, by using a force feedback joystick that simulated a handshake. Similarly, Smith and MacLean [11] used a haptic turning knob to investigate emotional expressions during a multi-player game and a simulated hand stroke. In both situations, participants were able to express and recognize specific emotions. However, Bickmore et al. [2] found that people were unable to recognize specific emotions from an air-bladder system that squeezed someones hand. The authors suggest that this might be due to the fact that their system did not have the degrees of freedom necessary to reliably convey specific emotions. Currently, research into the expression of emotions through mediated touch has focussed on touches applied to the hand in which the movements of the arms, hands and fingers are important $[1,11]$. This approach contrasts with earlier studies into the communication of emotions through touch between two co-located individuals, where touches were applied mainly to the forearm $[6,7]$. Our aim is to supplement earlier work on the expression of emotions using haptic feedback technology $[1,11]$, by using different actuators (i.e. vibration motors) applied to a different body location (i.e. the forearm). In order to overcome some of the limitations of expressing emotions through mediated touch, we used a custom-built interface, the TaSST (Tactile Sleeve for Social Touch) that should offer users more freedom of expression [8].

\section{The TaSST}

The TaSST 1.5 (Figure 1) [8] consists of a force sensitive input layer and a vibration motor output layer. Applying force to the 12 conductive wool sensor compartments, controls the intensity of vibration of 12 perpendicularly placed vibration motors. The grid of vibration motors matches the sensor grid, so that touches to the input layer match the location on the output layer.

\section{Expressing Emotions Through Mediated Touch}

We used the TaSST as an interface for participants to express emotions through mediated touch. While the TaSST is a custom built device we felt that the design was generic enough (i.e. coupling force sensors to vibration motors) to yield valuable insights regarding the expression of emotions through haptic technology. Our approach differs from that of Bailenson et al. [1] which focussed on the kinesthetic subsystem of the tactile sense. The TaSST, on the other hand, only stimulates mechanoreceptors in the skin, and is thereby focussed on the cutaneous subsystem [4]. Moreover, the TaSST is worn on the forearm, which has been found to be a suitable location for social touch to occur $[6,7]$. We designed a study in which participants expressed eight different emotions, taken from [6]. The emotion words used were: anger, fear happiness, sadness, disgust, love, gratitude, and sympathy. These emotion words were chosen because they have been found to be communicable through touch $[6,7]$. We used custom software to record expressions of emotion using the input layer of the TaSST. 


\begin{tabular}{|c|}
\hline Metrics \\
\hline $\begin{array}{l}\text { Average number of sensors: The } \\
\text { average number of sensors in the } 4 \\
\text { by } 3 \text { grid that was activated during } \\
\text { the expression of each emotion. A } \\
\text { high score would indicate that par- } \\
\text { ticipants used a lot of surface area to } \\
\text { express the emotion, whereas a low } \\
\text { score would indicate that the touch } \\
\text { was restricted to a certain area. }\end{array}$ \\
\hline $\begin{array}{l}\text { Average gap duration: The aver- } \\
\text { age duration (in milliseconds) of the } \\
\text { time that elapses between the acti- } \\
\text { vation of two or more sensors. A } \\
\text { high score would indicate that par- } \\
\text { ticipants lifted their hand off the in- } \\
\text { put layer between touches, whereas a } \\
\text { low score would indicate that partic- } \\
\text { ipants moved their hand from sensor } \\
\text { to sensor while in contact with the } \\
\text { input layer. }\end{array}$ \\
\hline $\begin{array}{l}\text { Average duration: The average du- } \\
\text { ration (in milliseconds) of the expres- } \\
\text { sion of each emotionin its entirety. } \\
\text { Measured from the first until the last } \\
\text { moment of contact with the input } \\
\text { layer. }\end{array}$ \\
\hline $\begin{array}{l}\text { Average intensity: The force (arbi- } \\
\text { trary unit, between } 0-255 \text { ) applied to } \\
\text { each sensor averaged over all sensors } \\
\text { activated in the expression of an emo- } \\
\text { tion. A high score would indicate } \\
\text { that participants used more forceful } \\
\text { touches overall, whereas a low score } \\
\text { would indicate more subtle touches. }\end{array}$ \\
\hline $\begin{array}{l}\text { Average number of recordings: The } \\
\text { average number of times participants } \\
\text { recorded an emotion. A high score } \\
\text { would indicate difficulty in expressing } \\
\text { an emotion, a low score would indi- } \\
\text { cate the emotion was relatively easy } \\
\text { to express. }\end{array}$ \\
\hline
\end{tabular}

Table 1: The metrics used to analyse data from the experiment.
These expressions could then be played back through the output layer of the same sleeve. We had participants express, and record the eight emotions as many times as they liked, until they were satisfied with the result.

\section{Participants}

The study featured 16 participants ( 11 male, 5 female) with a mean age of $28.13(\mathrm{SD}=9.18)$. Participants were all staff members and students from two universities.

\section{Materials}

A single TaSST sleeve, consisting of an input and output layer, was used for the experiment. A simple software interface was created using Python, to allow participants to record and play back touches using the TaSST. An online survey was used to ask questions to participants during the study.

\section{Procedures}

First the participant signed an informed consent sheet, and was given a written explanation of the procedures. Next the TaSST was attached to the participants arm (see Figure 1). We told participants that it would be their task to express a number of emotions using the TaSST. It was explained that these expressions would be recorded and played back to other participants, who's task it was to recognize the emotion. Before expressing the emotions, participants were given the chance to try out the TaSST and the recording program. Participant were required to click the record button, touch the input layer of the TaSST, click the stop button, and then click the play button to feel the touch being played back through the output layer. After this trial session, the recording program would show one of eight random emotion words. It was participants task to express this emotion following the same recording procedure as in the trial session. Participant could click the play button to play back the recorded touch through the output layer, and decide to either record a new touch and discard the previous one, or move on to the next emotion word. After having successfully recorded an emotion participants were asked to answer two questions. The first question regarded participants confidence in the expression ("How well were you able to express this emotion?"), and was rated on a 7-point Likert scale ranging from 1 (Not at all) to 7 (Perfectly). The second question was an open-ended question, and asked participants to describe the touches they applied ("Describe, in your own words, what sort of touches you used to express this emotion"). After recording all eight emotions, participants indicated their age and gender. During the procedure, participants wore headphones playing white noise to block out the sound produced by the vibration motors.

Data analysis

Based on the final recording for each emotion by each participant, we computed a number of metrics. The metric 'number of recordings' was used as an additional indication for the difficulty of expressing certain emotions. The metrics are described in Table 1. For the analysis of the metrics we adopted an approach similar to Bailenson et al. [1], where we first ran a series of repeated measures ANOVA's for all metrics, as well as for the confidence ratings. As noted by Bailenson et al., doing such an analysis with 8 emotions is a highly conservative test, especially considering the relatively small sample size. In this analysis only the number of sensors metric showed a significant result $(F(7,98)=2.6, p<.05)$. Therefore, a less conservative pairwise comparison was used (see also [1]). 


\begin{tabular}{|l|r|r|}
\hline Emotion & $\mathrm{M}$ & $\mathrm{SD}$ \\
\hline Anger & 4.88 & 1.36 \\
\hline Fear & 4.44 & 1.09 \\
\hline Sadness & 4.25 & 1.18 \\
\hline Happiness & 4.25 & 1.39 \\
\hline Love & 4.25 & 1.53 \\
\hline Disgust & 3.75 & 1.73 \\
\hline Gratitude & 3.69 & 1.58 \\
\hline Sympathy & 3.69 & 1.70 \\
\hline
\end{tabular}

Table 2: Mean confidence ratings and standard deviations (7-point scale) for all emotions. 1 $=$ not at all, $7=$ perfectly

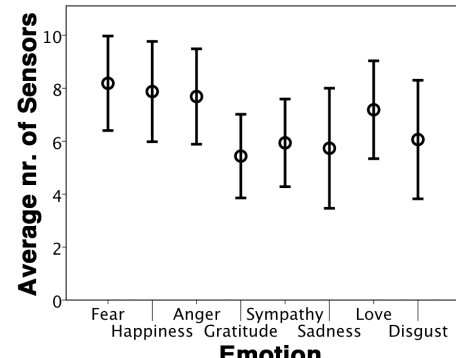

Figure 2: Average number of sensors activated for each emotion. Bars indicate the $95 \%$ confidence interval.

\section{Results: confidence ratings}

Overall, participants were moderately confident about the expressions, but less so for disgust, and the pro-social emotions gratitude and sympathy. For the basic emotions, these findings match earlier findings from [1]. Pair-wise comparisons revealed that anger was significantly easier to express than gratitude $(t(15)=3.23, p<.01)$, and sympathy $(t(15)=2.76, p<.05)$. Moreover, participants needed significantly $(t(15)=-2.28, p<.05)$ less recordings for anger $(M=2.38)$, than for gratitude $(M=$ 4.44).

\section{Results: metrics}

Pair-wise comparisons for the metrics showed that participants were to some extent capable of distinguishing different expressions of emotion using the TaSST. Figures 2-5 show the means and 95\% confidence intervals for the metrics. Figure 2 reveals that to express fear $(M=8.19)$, happiness $(M=7.88)$, and anger $(M=7.69)$, participants touched a significantly $(p<.05)$ larger surface area than for the expression of gratitude $(M=5.44)$, sympathy $(M=5.94)$, sadness $(M=5.73)$. Figure 3 shows that most emotions were expressed with relatively equal intensity. However, for sympathy $(M=111,00)$, participants used significantly $(p<.05)$ more force when compared to fear $(M=103.69)$, anger $(M=100.06)$, and gratitude $(M=102.13)$. Figure 4 indicates that for the gap duration (i.e. the duration between touches to the TaSST's surface) anger $(\mathrm{M}=763,13)$ had a significantly $(p<.05)$ shorter gap duration than happiness $(\mathrm{M}=1861.50)$ and love $(\mathrm{M}=1705.75)$. Similarly, disgust $(\mathrm{M}=458.50)$ had a significantly $(p<.05)$ shorter duration than fear $(\mathrm{M}=1370.50)$, happiness $(\mathrm{M}=$ 1861.50 , sadness $(M=2032.00)$ and love (1705.75).

Although in the case of disgust, this is most likely due to the fact that the total duration of the touches for disgust was relatively low, as can be observed from Figure 5. Indeed, Figure 5 shows that disgust $(M=2123.94)$ had a significantly $(p<.05)$ shorter total duration than anger $(\mathrm{M}=3498.69)$ and love $(\mathrm{M}=4794.50)$. Furthermore, love had a significantly $(p<.05)$ longer total duration than anger and gratitude $(M=2541.63)$.

Results: open-ended questions

We first applied a stemming procedure (i.e. grouping together derivatives of the same word) so that words like grab, grabbing, and grabbed, were combined into the concept grabbing. Next, we combined synonymous terms (e.g. hard and firm). For the remaining terms, we identified common themes in the responses. Participants' comments were all related to either timing, intensity, type, and/or location of touches. In addition, in some cases participants made comments that can best be described as symbolic (e.g. a handshake). Finally, we removed any descriptions that occurred only once, leaving the responses that most clearly described the participants touches. Because of space restrictions we will not present all comments made by participants here. Instead, we will discuss each emotion based on the metrics and link this to the open-ended responses.

Anger was described as a long $(4 x)$, hard (9x) touch, covering multiple squares (5x). Participants characterized their touches as squeezing (3x) and hitting (3x). Indeed, anger covered a significantly larger surface area than gratitude, sympathy and sadness. However, anger was only significantly longer in duration than disgust. The high intensity described by participants was not supported by the metrics.

Fear was most clearly described as a short $(3 x)$, hard $(3 x)$ touch, in the form of either squeezing $(2 x)$, grabbing $(2 x)$, or pressing $(2 x)$. Looking at the symbolic descriptions it 


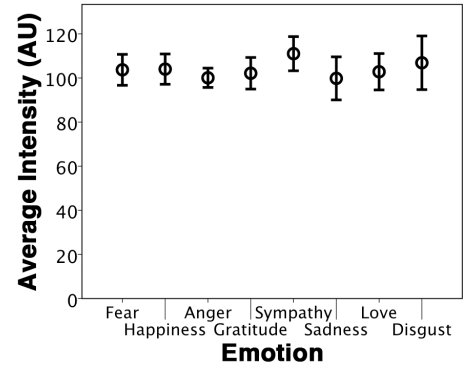

Figure 3: Average intensity for each emotion. Bars indicate the $95 \%$ confidence interval.

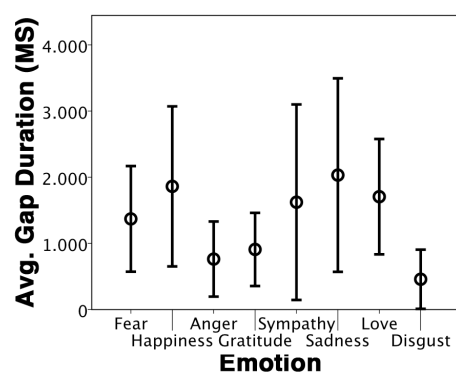

Figure 4: Average gap duration for each emotion. Bars indicate the $95 \%$ confidence interval.

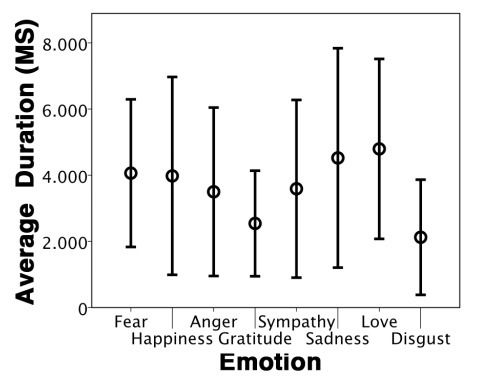

Figure 5: Average duration for each emotion. Bars indicate the $95 \%$ confidence interval. seemed participants tried to express a startle response (startled $(2 x)$ ). These observations were supported by the number of sensors metric, which showed fear covered a significantly larger surface area than gratitude, sympathy and sadness. This is most likely due to the fact that the types of touches described for fear cover a relatively large surface area. The relatively low gap duration also supports the types of touches described.

Happiness was characterized by fast $(5 x)$ touches in random (7x) locations. Participants described these touches as playful (2x) and as skipping (2x). Happiness covered a significantly larger surface area than gratitude, sympathy and sadness. This can be explained by participants 'skipping' over the sleeve in multiple random locations. A relatively high gap duration lends support to this observation (i.e. significantly higher than anger and disgust).

Sadness was characterized as short $(2 x)$, slow $(2 x)$, soft $(3 x)$, grabbing $(2 x)$ touches to one square $(2 x)$. Symbolically sadness was described as crying $(3 x)$, and passive $(2 x)$. The passiveness and small surface area were supported by the metrics as the number of sensors metric showed that sadness covered a significantly smaller surface area than fear, happiness, and anger.

Disgust was described best as short (6x), pushing away $(2 x)$, or pressing $(2 x)$ touches. Indeed disgust's gap duration was significantly shorter than fear, happiness, sadness, and love. Disgust also had a significantly shorter duration than anger and love. It seems disgust is most clearly expressed by as little touching as possible.

Love was most clearly described as soft (3x), stroking $(6 x)$ touches to multiple squares $(7 x)$. Though the softness and surface area of the touch were not supported by the metrics, touches for love lasted significantly longer than for anger, disgust, and gratitude. Intuitively it makes sense that touches for love would last longer, because, as the Darwin quote in the introduction explains, feelings of love invite touching.

Gratitude was expressed by participants as short (4x), calm (4x), pressing $(3 x)$, which was intended to symbolize a handshake $(4 x)$. Gratitude covered a smaller surface area than fear, happiness, and anger. It seems the pressing type of touch was therefore restricted to a smaller area. The brief duration only became apparent when compared to love. The more symbolic nature of the expression of this emotion seems to have made it hard to express using the TaSST, as was indicated by the relatively low confidence score.

Finally, sympathy was described as soft $(2 x)$, calm $(2 x)$, repetitive $(2 x)$, touches with long pauses $(2 x)$, best described as stroking $(3 x)$ or patting $(3 x)$. Somewhat surprising is that sympathy was expressed with significantly higher intensity than fear, anger, and gratitude. A potential explanation is that participants underestimated the amount of force they applied when applying the stroking, and patting touches.

The open-ended questions provided some interesting insights into the differences found for the metrics. What is encouraging is that the open-ended responses for the type of touch matched fairly well with earlier research into the expression of emotions in unmediated touch (Table 3 ).

\section{Conclusions and future work}

The results from the study described in this paper provide some evidence that participants could successfully express different emotions using the TaSST. Though these results are not conclusive, they do provide valuable insights into 


\begin{tabular}{|l|l|l|}
\hline Emotion & Current & {$[7]$} \\
\hline Anger & $\begin{array}{l}\text { Squeezing } \\
\text { Hitting } \\
\text { Pressing }\end{array}$ & $\begin{array}{l}\text { Hitting } \\
\text { Squeezing } \\
\text { Trembling }\end{array}$ \\
\hline Fear & $\begin{array}{l}\text { Squeezing } \\
\text { Grabbing } \\
\text { Pressing }\end{array}$ & $\begin{array}{l}\text { Trembling } \\
\text { Squeezing } \\
\text { Shaking }\end{array}$ \\
\hline Happiness & Grabbing & $\begin{array}{l}\text { Swinging } \\
\text { Shaking } \\
\text { Lifting }\end{array}$ \\
\hline Sadness & Grabbing & $\begin{array}{l}\text { Stroking } \\
\text { Squeezing } \\
\text { Lifting }\end{array}$ \\
\hline Disgust & $\begin{array}{l}\text { Pushing } \\
\text { Pressing }\end{array}$ & $\begin{array}{l}\text { Pushing } \\
\text { Lifting } \\
\text { Tapping }\end{array}$ \\
\hline Love & Stroking & $\begin{array}{l}\text { Stroking } \\
\text { Finger } \\
\text { interlocking } \\
\text { Rubbing }\end{array}$ \\
\hline Gratitude & $\begin{array}{l}\text { Pressing } \\
\text { Stroking } \\
\text { Grabbing }\end{array}$ & $\begin{array}{l}\text { Shaking } \\
\text { Lifting } \\
\text { Squeezing }\end{array}$ \\
\hline Sympathy & $\begin{array}{l}\text { Stroking } \\
\text { Patting } \\
\text { Holding }\end{array}$ & $\begin{array}{l}\text { Patting } \\
\text { Stroking } \\
\text { Rubbing }\end{array}$ \\
\hline
\end{tabular}

Table 3: Descriptions of the touch types for each emotion in the current study compared to those from Hertenstein et al. [7] the tactile expression of emotions. The expression of emotions through mediated touch may not only be possible through force-feedback interfaces $[1,11]$, but also through interfaces that use more simple actuators (i.e. vibration motors), as is the case with the TaSST. The next steps in this project are to do additional analyses on the collected data. For example, the metrics presented in this paper were all from the final recording made by participants. It would be interesting to also look at the first recording, and see how much participants changed their expression from the first to the last recording. Furthermore, future work will include having another group of participants attempt to recognize emotions from the recorded expressions. Here, it would be interesting to also see if participants describe the recordings in a similar fashion as participants in the current study did. Finally, we hope to make improvements to the TaSST. What stood out most in this study, is that participants had trouble to differentiate the intensity of the expressions. We are currently working on improving the sensitivity of the input layer of the TaSST, by using the conductive wool as a capacitive sensor.

\section{Acknowledgements}

This publication was supported by the Dutch national program COMMIT.

\section{References}

[1] Bailenson, J. N., Yee, N., Brave, S., Merget, D., and Koslow, D. Virtual interpersonal touch: Expressing and recognizing emotions through haptic devices. Human-Computer Interaction 22, 3 (2007), 325-353.

[2] Bickmore, T. W., Fernando, R., Ring, L., and Schulman, D. Empathic Touch by Relational Agents.
IEEE Transactions on Affective Computing 1, 1 (2010), 60-71.

[3] Darwin, C. The Expression of Emotions in Man and Animals. Harper Collins, 1998 (Original work published in 1872).

[4] Haans, A., and IJsselsteijn, W. A. Mediated social touch: a review of current research and future directions. Virtual Reality 9, 2-3 (2006), 149-159.

[5] Hertenstein, M. J., and Campos, J. J. Emotion regulation via maternal touch. Infancy 2, 4 (2001), 549-566.

[6] Hertenstein, M. J., Holmes, R., McCullough, M., and Keltner, D. The communication of emotion via touch. Emotion 9, 4 (2009), 566-573.

[7] Hertenstein, M. J., Keltner, D., App, B., Bulleit, B. and Jaskolka, A. R. Touch communicates distinct emotions. Emotion 6, 3 (2006), 528-33.

[8] Huisman, G., Darriba Frederiks, A., Van Dijk, E. M. A. G., Heylen, D. K. J., and Kröse, B. J. A. The TaSST - Tactile Sleeve for Social Touch. Accepted for publication in Proceedings of WHC'13 (2013).

[9] Morrison, I., Löken, L., and Olausson, H. The skin as a social organ. Experimental Brain Research 204 (2010), 305-314.

[10] Russell, J. A., Bachorowski, J. A., and Fernandez-Dols, J.-M. Facial and vocal expressions of emotion. Annual Review of Psychology 54, 1 (2003), 329.

[11] Smith, J., and MacLean, K. Communicating emotion through a haptic link: Design space and methodology. International Journal of Human-Computer Studies 65, 4 (2007), 376-387. 